\title{
Identification and characterization of the nitrate assimilation genes in the isolate of Streptomyces griseorubens JSD-1
}

Haiwei Feng ${ }^{1,2,3}$, Yujing Sun ${ }^{1}$, Yuee Zhi ${ }^{1,2,3}$, Xing Wei ${ }^{1,2,3}$, Yanqing Luo ${ }^{1,2,3}$, Liang Mao ${ }^{1,2,3}$ and Pei Zhou ${ }^{1,2,3^{*}}$

\begin{abstract}
Background: Streptomyces griseorubens JSD-1 is a novel actinomycete isolated from soil that can utilize nitrate as its sole nitrogen source for growth and these nitrate assimilation genes active in this biotransformation are expected to be crucial. However, little is known about its genomic or genetic background related to nitrogen metabolism in this isolate. Thus, this study concentrates on identification and characterization of genes involved in nitrate assimilation.

Results: To investigate the molecular mechanism of nitrate metabolism, genome sequencing was performed by Illumina Miseq platform. Then the draft genome of a single linear chromosome with 8,463,223 bp and an average $\mathrm{G}+\mathrm{C}$ content of $72.42 \%$ was obtained, which has been deposited at GenBank under the accession number JJMG00000000. Sequences of nitrate assimilation proteins such as nitrate reductase (EC 1.7.99.4), nitrite reductase (EC 1.7.1.4), glutamine synthetase (EC 6.3.1.2), glutamate synthase (EC 1.4.1.13) and glutamate dehydrogenase (EC 1.4.1.2) were acquired. All proteins were predicted to be intracellular enzymes and their sequences were highly identical to those from their similar species owing to the conservative character. Putative 3D structures of these proteins were also modeled based on the templates with the most identities in the PDB database. Through KEGG annotated map, these proteins proved to be located on the key positions of nitrogen metabolic signaling pathway. Finally, quantitative RT-PCR indicated that expression responses of all genes were up-regulated generally and significantly when stimulated with nitrate.
\end{abstract}

Conclusion: In this manuscript, we describe the genome features of an isolate of S. griseorubens JSD-1 following with identification and characterization of these nitrate assimilation proteins such as nitrate reductase, nitrite reductase, glutamine synthetase, glutamate synthase and glutamate dehydrogenase accounts for the ability to utilize nitrate as its sole nitrogen source for growth through cellular localization, multiple sequence alignment, putative 3D modeling and quantitative RT-PCR. In summary, our findings provide the genomic and genetic background of utilizing nitrate of this strain.

Keywords: Streptomyces griseorubens, Genome sequencing, Nitrogen metabolism, Nitrate reductase, Nitrite reductase, Glutamine synthetase, Glutamate synthase, Glutamate dehydrogenase

\section{Background}

Nutritionally, physically and biologically, soil is a particularly complex and variable environment, of which the indispensable component is inorganic salts. Among these numerous elements, nitrogen is crucial as it supplies essential nutrient for plants and microorganisms. Nitrogen

\footnotetext{
* Correspondence: peizhousjtu@163.com

'School of Agriculture and Biology, Shanghai Jiao Tong University, Shanghai 200240, China

${ }^{2}$ Key Laboratory of Urban Agriculture (South), Ministry of Agriculture,

Shanghai Jiao Tong University, Shanghai 200240, China

Full list of author information is available at the end of the article
}

in soil is existed in the organic or inorganic forms. Generally, the inorganic nitrogen mainly includes nitrate and ammonium. Nitrate is preferentially found in temperate climates, while ammonium is dominant in a number of tropical soil types.

Nitrate is metabolized through various reduction processes in organisms. Nitrate reduction, the most important stages of nitrogen recycle in nature, has various functions as follows: (1) as a source of nitrogen by utilization of $\mathrm{NO}_{3}{ }^{-}$(nitrate assimilation); (2) as terminal acceptor of electrons by producing metabolic energy during $\mathrm{NO}_{3}{ }^{-}$ utilization (nitrate respiration); (3) maintain oxidation 
reduction balance by dissipating excessed energy (nitrate dissimilation). Totally, three different nitrate reducing systems (Nas, Nar and Nap) have been described in microorganisms [1-4]. Assimilatory nitrate reductases (Nas) are usually cytoplasmic enzymes stimulated by nitrate or nitrite and repressed by ammonium with the character of using either $\mathrm{NAD}(\mathrm{P}) \mathrm{H}$ or ferredoxin as physiological electron donor. Membrane-bounded nitrate reductases (Nar) are mainly involved in anaerobic nitrate respiration and denitrification. Finally, periplasmic dissimilatory reductases (Nap) contribute to redox balancing and aerobic or anaerobic denitrification.

Nitrate assimilation is a key process of nitrogen recycling carried out by higher plants [5,6], algae [7], yeasts $[8,9]$, and bacteria $[10,11]$. The assimilatory process starts when nitrate is transported into the cell by an active transport system. Nitrate is converted to nitrite with the function of nitrate reductase following with the reduction of nitrite to ammonia and then the conversion of ammonia to glutamine through nitrite reductase and glutamine synthetase. Finally, glutamine is transformed into glutamate by glutamate synthase [12]. Both glutamine and glutamate are the essential substrates for protein synthesis and energy metabolism. For example, glutamate is metabolized into ammonia and $\alpha$-ketoglutarate with the function of glutamate dehydrogenase.

Up to now, bacterial assimilatory nitrate reductases have been classified into at least three categories according to the number of electron transfer cofactors bounded by the catalytic bis-molybdopterin guanine dinucleotide subunit and the nature of the probable electron donors to each enzyme, which are typified by their sources of Synechococcus sp. [13], Klebsiella oxytoca [14], and Bacillus sp. [4,15].

Streptomycetes are a genus of Gam-positive bacteria that form filamentous mycelium-like eukaryote fungi. They are the most numerous and ubiquitous soil bacteria, which are crucial in the environment because of their broad ranges of metabolic processes and biotransformations. To our knowledge, genetic basic related to the metabolism of nitrate in streptomycetes has rarely been reported.

In this study, genome sequencing of our recently isolated soil strain Streptomyces griseorubens JSD-1 that could utilize nitrate as the unique nitrogen source for growth, was carried out for identification and characterization of genes participating in the nitrate metabolism.

\section{Results and discussion}

\section{Identification and characterization of the isolate}

A novel strain, designated as JSD-1, was isolated on the basal medium owing to its ability to grow efficiently upon the medium with the addition of nitrate as the unique nitrogen source. Through the combination of $16 \mathrm{~S}$ rRNA sequencing as well as its morphological and physiological characters, the isolate was identified as S. griseorubens [16].

In addition, $S$. griseorubens JSD-1 could metabolized $69 \%$ nitrate totally during the whole cultivation (Figure 1), indicating that this isolate had significant tolerance and metabolic capability towards nitrate of high concentration (100 mM).

\section{Genome sequencing and bio-informatics analysis of S. griseorubens JSD-1}

Genome sequencing of S. griseorubens JSD-1 was performed by Illumina Miseq $2 \times 250$ bp platform by Personal biotechnology Co., Ltd. A total of 6,432,848 reads including up to $2,209 \mathrm{Mb}$ clean data were generated, which represented a 263.0-fold average coverage of the whole genome. The assembled genome contained 2 scaffolds and 246 contigs. The $\mathrm{N}_{50}$ length of contigs was $53,294 \mathrm{bp}$ and that of scaffolds was $7,563,100 \mathrm{bp}$. Finally, we obtained the draft genome map of $S$. griseorubens with a single linear chromosome of $8,463,223 \mathrm{bp}$, which was of smaller size than the ones of S. coelicolor A3(2) (8.7 Mb), S. avermitilis MA-4680 (9.0 Mb), or S. griseus IFO 13350 (8.5 Mb) [17-19]. Besides, the G+C content of was high up to $72.42 \%$, a typical character of streptomycetes [17-22]. Analysis of the genome revealed that it contained 7159 protein-coding sequences (CDS). Among these CDSs, 4587 proteins could be assigned to clusters of orthologous groups (COG) families [23].

Genome features were shown in Table 1, which has been deposited in GenBank under accession number JJMG00000000. Since successfully obtaining its draft genome, emphasis was put on identification and characterization of these nitrate assimilation genes.

\section{Cellular localization}

No natural signal peptide sequence could be judged from these analyzed proteins on the $\mathrm{N}$-terminals (Additional file 1: Figure S1). Therefore, all nitrate assimilation proteins were predicted to be intracellular enzymes, which was accordance with previous reports [10-12].

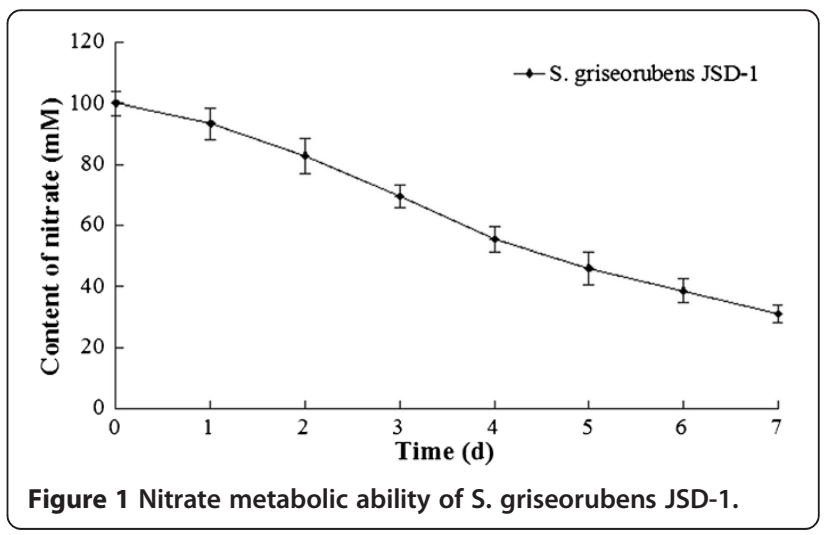


Table 1 Genome features of S. griseorubens JSD-1

\begin{tabular}{ll}
\hline Attribute & Value \\
\hline Total number of contigs & 246 \\
Total bases in contigs (bp) & $7,600,227$ \\
Longest contig length (bp) & 328,776 \\
$\mathrm{~N}_{20}$ length (bp) & 104,101 \\
$\mathrm{~N}_{50}$ length (bp) & 53,294 \\
$\mathrm{~N}_{90}$ length (bp) & 16,099 \\
Sequences greater than $1 \mathrm{~kb}$ & 243 \\
Average coverage & 263 \\
DNA G+C content (\%) & 72.42 \\
Protein coding genes & 7,159 \\
Genes with predicted function & 4,587 \\
\hline
\end{tabular}

\section{Multiple sequence alignment}

After obtaining the assembled genome, genes were predicted and annotated by BLASTP to find out the nitrate assimilation genes. Therefore, genes found were nitrate reductase electron transfer subunit NarB (2394 bp), nitrate reductase catalytic subunit $\operatorname{NarC}(2127 \mathrm{bp})$, nitrite reductase $[\mathrm{NAD}(\mathrm{P}) \mathrm{H}]$ large subunit $\mathrm{NirD}(2601 \mathrm{bp})$, nitrite reductase $[\mathrm{NAD}(\mathrm{P}) \mathrm{H}]$ small subunit NirE (354 bp), glutamine synthetase GlnA (1377 bp), glutamate synthase large subunit GltF (4512 bp), glutamate synthase small subunit GltG (1491 bp), and glutamate dehydrogenase GdhH (4950 bp). Since protein sequences were obtained. Searches against the $\mathrm{Nr}$ database were performed to find out the top three sequences with the most identities for the following multiple sequence alignments.

As nitrate reductase, nitrite reductase, and glutamate synthase were dimer proteins consisting of two subunits, NarB, NirD, GlnA, GltG, and GdhH were used to represent the five analyzed proteins for further study. Results in Table 2 were summarized as follows: (1) the top three proteins with the most identities to nitrate reductase electron transfer subunit (NarB) were from Streptomyces sp. FxanaD5 (WP_019527265) of 95\% identity, S. gancidicus (WP_006133010) of 94\% identity, and S. griseoflavus (WP_004935829) of 89\% identity; (2) the top three proteins with the most identities to nitrite reductase large subunit (NirD) were from Streptomyces sp. FxanaD5 (WP_019523194) of 97\% identity, S. chartreusis (WP 010042208) of 94\% identity, and S. gancidicus (WP 006129667) of $94 \%$ identity; (3) the top three proteins with the most identities to glutamine synthetase (GlnA) were from Streptomyces sp. FxanaD5 (WP_019522401), S. gancidicus (WP_006130087), and S. griseoflavus (WP_004931998) with the same identity of 98\%; (4) the top three proteins with the most identities to glutamate synthase small subunit (GltG) were from Streptomyces sp. FxanaD5 (WP_019525300) following S. gancidicus (WP_006135305) and Streptomyces sp.
Table 2 Multiple sequence alignments of nitrate assimilation proteins

\begin{tabular}{|c|c|c|}
\hline Proteins & $\begin{array}{l}\text { Significant alignments (Accession } \\
\text { number) }\end{array}$ & $\begin{array}{l}\text { Alignment } \\
\text { identifies (\%) }\end{array}$ \\
\hline \multirow[t]{3}{*}{ NarB } & Streptomyces sp. FxanaD5 (WP_019527265) & 756/797 (95\%) \\
\hline & Streptomyces gancidicus (WP_006133010) & 745/793 (94\%) \\
\hline & Streptomyces griseoflavus (WP_004935829) & $712 / 799(89 \%)$ \\
\hline \multirow[t]{3}{*}{ NarC } & Streptomyces gancidicus (WP_006129675) & $670 / 708(95 \%)$ \\
\hline & Streptomyces griseoflavus (WP_004931583) & 622/694 (90\%) \\
\hline & Streptomyces viridosporus (WP_016826372) & $632 / 722(88 \%)$ \\
\hline \multirow[t]{3}{*}{ NirD } & Streptomyces sp. FxanaD5 (WP_019523194) & $839 / 866(97 \%)$ \\
\hline & Streptomyces chartreusis (WP_010042208) & $814 / 862(94 \%)$ \\
\hline & Streptomyces gancidicus (WP_006129667) & $821 / 869(94 \%)$ \\
\hline \multirow[t]{3}{*}{ NirE } & Streptomyces gancidicus (WP_006129666) & $111 / 117(95 \%)$ \\
\hline & Streptomyces sp. FxanaD5 (WP_019523193) & 107/117 (91\%) \\
\hline & Streptomyces sviceus (WP_007381873) & $94 / 117(80 \%)$ \\
\hline \multirow[t]{3}{*}{$\mathrm{G} \ln \mathrm{A}$} & Streptomyces sp. FxanaD5 (WP_019522401) & $449 / 458(98 \%)$ \\
\hline & Streptomyces gancidicus (WP_006130087) & $444 / 453(98 \%)$ \\
\hline & Streptomyces griseoflavus (WP_004931998) & $443 / 453(98 \%)$ \\
\hline \multirow[t]{3}{*}{ GltF } & Streptomyces sp. FxanaD5 (WP_019525478) & 1477/1503 (98\%) \\
\hline & Streptomyces gancidicus (WP_006135499) & 1470/1508 (97\%) \\
\hline & Streptomyces ghanaensis (WP_004989383) & 1414/1503 (94\%) \\
\hline \multirow[t]{3}{*}{ GltG } & Streptomyces sp. FxanaD5 (WP_019525300) & $471 / 495(95 \%)$ \\
\hline & Streptomyces gancidicus (WP_006135305) & $467 / 496(94 \%)$ \\
\hline & Streptomyces sp. Amel2xE9 (WP_019984065) & $436 / 496(88 \%)$ \\
\hline \multirow[t]{3}{*}{ GdhH } & Actinospica acidiphila (WP_033277556) & $1644 / 1649(99 \%)$ \\
\hline & Streptomyces sp. NRRL S-1314 (WP_031019546) & 1585/1648 (96\%) \\
\hline & Streptomyces gancidicus (WP_006132432) & $1566 / 1630(96 \%)$ \\
\hline
\end{tabular}

Amel2xE9 (WP_019984065) with the identities of 95\%, $94 \%$, and $88 \%$, respectively; (5) the top three proteins with the most identities to glutamate dehydrogenase (GdhH) were from A. acidiphila (WP_033277556), Streptomyces sp. NRRL S-1314 (WP_031019546), and S. gancidicus (WP_006132432) with the identities of 99\%, 96\%, and $96 \%$, respectively. Refer to Figure 2 for the visible alignment of nitrate reductase electron transfer subunit (NarB) and other results were also exhibited (Additional file 2: Figure S2; Additional file 3: Figure S3; Additional file 4: Figure S4; Additional file 5: Figure S5).

Since NarB, NirD, GlnA, GatG, and GdhH shared high identities with sequences of their similar strains in the primary structure, especially S. gancidicus, Streptomyces sp. FxanaD5, and S. griseoflavus, their sequences were inferred to be conservative during evolution. However, nitrite reductase $[\mathrm{NAD}(\mathrm{P}) \mathrm{H}]$ small subunit $(\mathrm{NirD})$ seemed to be only identical with S. gancidicus and Streptomyces sp. FxanaD5 as the identities dropped to $80 \%$ when aligned with other streptomycetes. It could be either the sequence was not universally functional annotated 


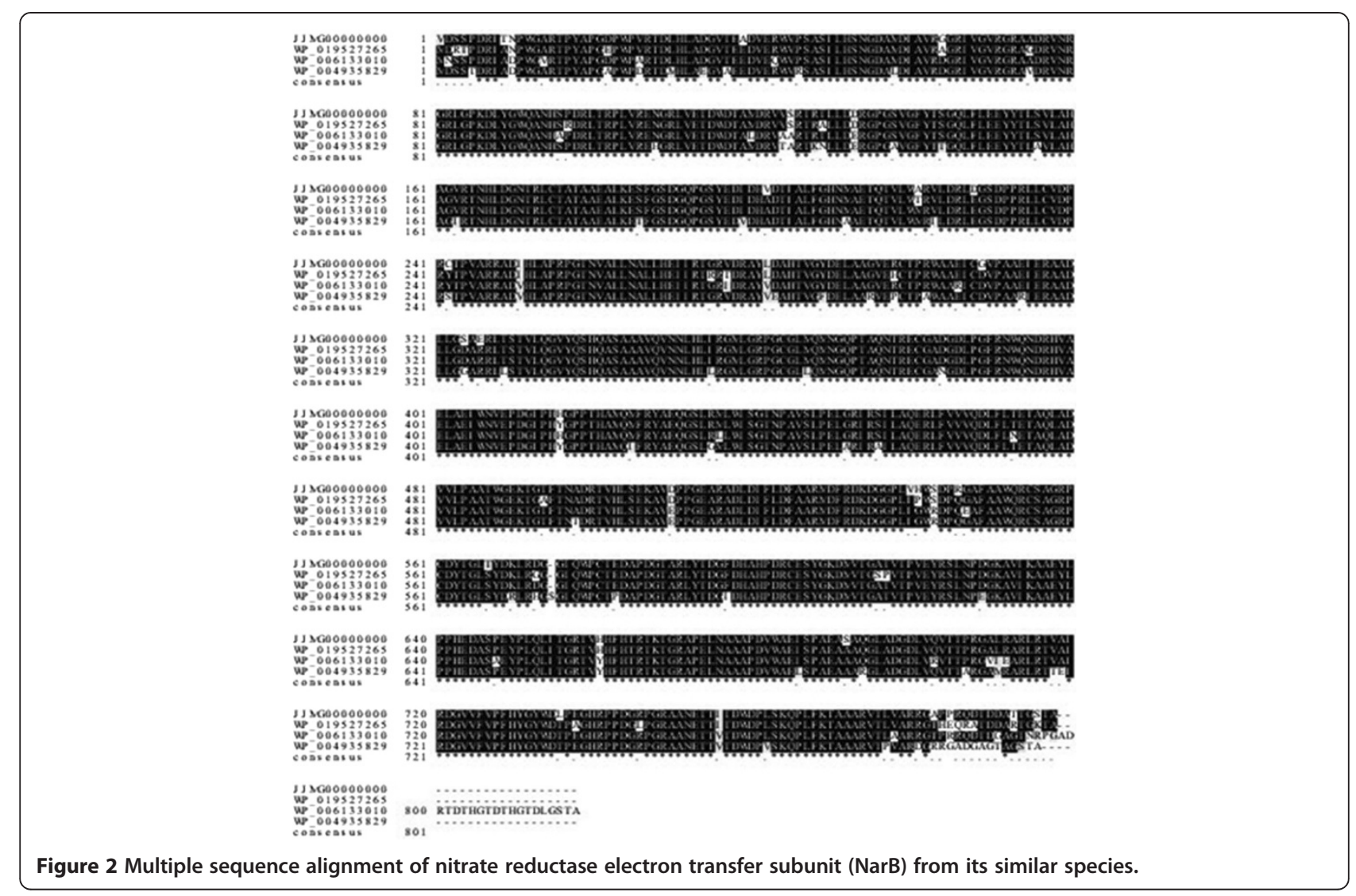

or it had other special functions [24], which needed to be further investigated.

\section{Putative 3D structure modeling}

After obtaining the sequences of these nitrate assimilation proteins (nitrate reductase, nitrite reductase, glutamine synthetase, glutamate synthase, and glutamate dehydrogenase), their putative 3D structures were modeled by PHYRE2 based on the most identical templates in the PDB database. By viewing the modeling results, a brief idea of how the 3D structures of these proteins might look like would be illustrated (Additional file 6: Figure S6).
All details were shown in Table 3. Putative 3D structure modelings of (1) NarB was generated based on the sequence residues from 37 to 777 with $89 \%$ coverage and $33 \%$ identity against the template c2v45A (2.40 ̊); (2) NirD was generated based on the sequence residues from 5 to 413 with $47 \%$ coverage and $26 \%$ identity against the template c3ntaA (2.01 $)$; (3) GlnA was generated based on the sequence residues from 4 to 452 with $96 \%$ coverage and $35 \%$ identity against the template c1fpyE (2.89 ̊); (4) GltG was generated based on sequence residues of 5 to 493 with $94 \%$ coverage and $21 \%$ identity against the template c1gthD (2.25 ̊); (5) GdhH was generated based on sequence residues of 732 to 1284

Table 3 Putative 3D modeling information of nitrate assimilation proteins

\begin{tabular}{llllll}
\hline Proteins & Residue range (AA) & Query coverage (\%) & Identity (\%) & Confidence (\%) & Template \\
\hline NarB & $37-777$ & $89 \%$ & $33 \%$ & $100 \%$ & $\mathrm{c} 2 \mathrm{v} 45 \mathrm{~A}(2.40 \AA)$ \\
NarC & $1-705$ & $99 \%$ & $34 \%$ & $100 \%$ & $\mathrm{c} 2 \mathrm{v} 45 \mathrm{~A}(2.40 \AA)$ \\
NirD & $5-413$ & $47 \%$ & $26 \%$ & $100 \%$ & $\mathrm{c} 3 \mathrm{ntaA}(2.01 \AA)$ \\
NirE & $18-116$ & $85 \%$ & $51 \%$ & $100 \%$ & $\mathrm{c} 4 \mathrm{aivA}(2.00 \AA)$ \\
GlnA & $4-452$ & $96 \%$ & $35 \%$ & $100 \%$ & $\mathrm{c} 1 \mathrm{fpyE}(2.89 \AA)$ \\
GltF & $11-1477$ & $96 \%$ & $46 \%$ & $100 \%$ & $\mathrm{c} \mathrm{vdcF}(9.50 \AA)$ \\
GltG & $5-493$ & $94 \%$ & $21 \%$ & $100 \%$ & $\mathrm{c} 1 \mathrm{gthD}(2.25 \AA)$ \\
GdhH & $732-1284$ & $33 \%$ & $18 \%$ & $100 \%$ & $\mathrm{c} 1 \mathrm{hrdA}(1.96 \AA)$ \\
\hline
\end{tabular}


with low coverage and identity of $33 \%$ and $18 \%$ against the template c1hrdA (1.96 ̊). All the predictions above were of $100 \%$ confidence with the modeling results.

Among these modelings, NirD, GltG, and GdhH shared low (below 30\%) identities of 26\%, $21 \%$, and even $18 \%$ with the templates although they all shared high similarities with their identical sequences in the primary structure (Table 2). It could be either there were not enough identical protein templates in the database or these proteins had rarely secondary structures [25]. Although the overall identities to the modeling templates were discriminating, it simply offered a brief demonstration of these proteins' 3D structures with $100 \%$ confidence, which indicated that all predictions were reliable and accurate.

\section{Location of nitrate assimilation proteins in KEGG metabolic pathway}

To investigate the location of these nitrate assimilation proteins in nitrogen metabolic pathway, a search was carried out in the KEGG database. Inferred from the KEGG map (Figure 3), nitrate reductase (EC 1.7.99.4), nitrite reductase (EC 1.7.1.4), glutamine synthetase (EC 1.3.1.2), glutamate synthase (EC 1.4.1.13) and glutamate dehydrogenase (EC 1.4.1.2) were located on the key positions of nitrogen metabolic pathway. The pathway could be summarized as follows: nitrate was transported into the cell through an active transport system following the reduction of nitrate to ammonium by nitrate reductase and nitrite reductase. Combined with glutamine acid, glutamine was formed by glutamine synthetase and then glutamine was converted into glutamate with the function of glutamate synthase [12]. Finally, glutamate was metabolized into ammonia and $\alpha$-ketoglutarate by glutamate dehydrogenase. Both glutamine and glutamate could be directly utilized for protein bio-synthesis and other biochemistry processes such as tricarboxylic acid cycle.

\section{Differential expression patterns of the analyzed proteins}

To further investigate the impact of nitrate concentrations (10 mM, $30 \mathrm{mM}, 50 \mathrm{mM}$, and $100 \mathrm{mM}$ ) and cultivation duration on the expression patterns of nitrate assimilation proteins, quantitative RT-PCR was performed. Generally, expression of nitrate reductase and nitrite reductase were up-regulated with the concentrations of nitrate increasing. However, expression patterns of glutamine synthetase and glutamate synthase reached the highest when stimulated by $50 \mathrm{mM}$ nitrate. It was inferred that mass of glutamine or glutamate newly formed that beyond the capacity of biosynthesis were accumulated through nitrate metabolic pathway, and glutamine or glutamate excessed led to the substrate feedback inhibition [26]. Thereafter, expression levels of glutamine synthetase and glutamate synthase were down-regulated. Glutamate dehydrogenase exhibited the similar tendency of expression with the peak concentration of $30 \mathrm{mM}$ nitrate for the mass of exceed ammonia sourced from the nitrite reduction and glutamate dehydrogenation. However, expression patterns of nitrate reductase or nitrite reductase were still up-regulated even when nitrate reached up to $100 \mathrm{mM}$. As nitrate or nitrite of high concentrations were extremely poisonous to cells, bio-transforming nitrate or nitrite immediately was urgently needed [27]. It was supposed to be the genetic basic accounts for its significant tolerance towards nitrate or nitrite of high concentrations.

Results also clearly demonstrated that cultivation duration had significant influence on the expression patterns of these analyzed proteins. When exposed to nitrate of low concentrations (10 $\mathrm{mM}$ or $30 \mathrm{mM})$, expression responses of these proteins showed a consistent tendency of

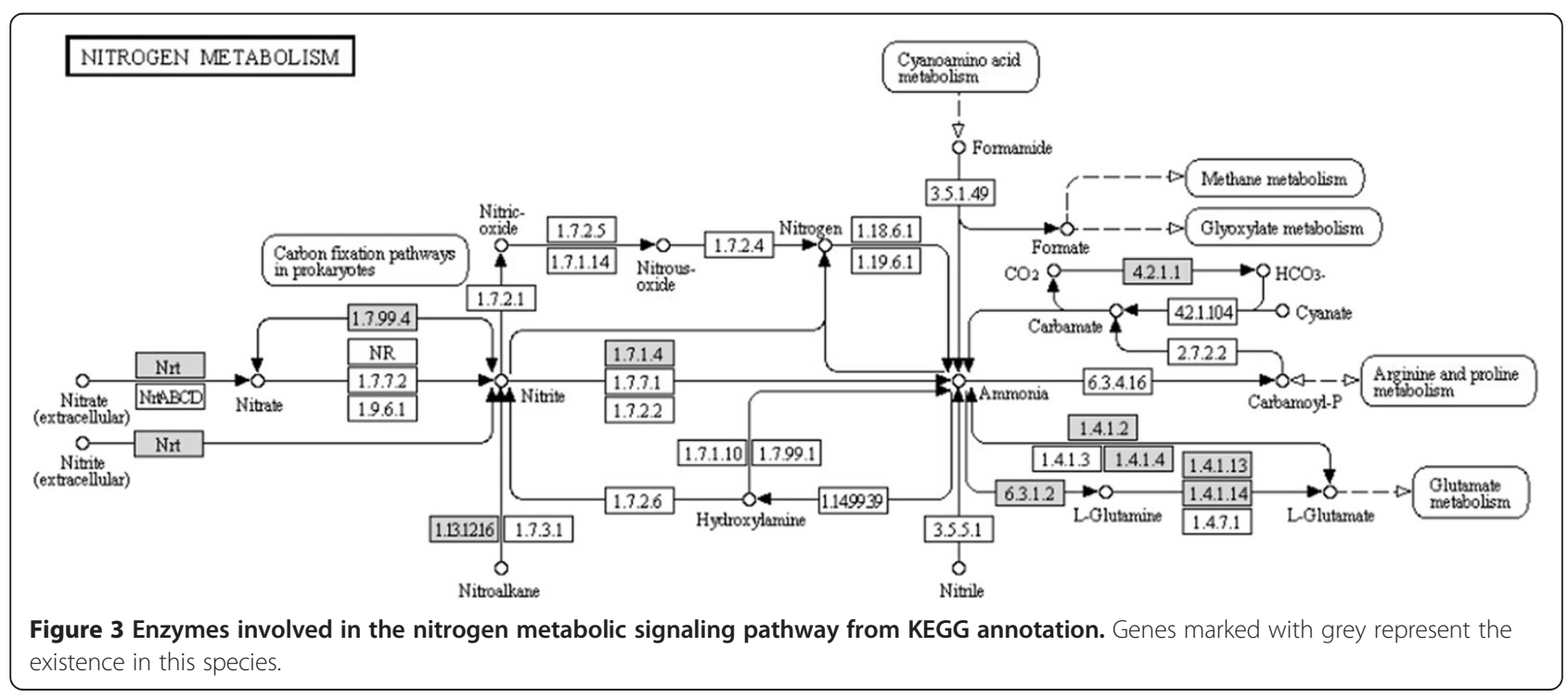


rising firstly and then falling with the peaks occurring at around $48 \mathrm{~h}$ or $60 \mathrm{~h}$. Expression levels were down regulated due to the lack of substrate after certain cultivation period [28,29]. With concentrations of nitrate rising, expression of nitrate reductase and nitrite reductase exhibited an rising tendency. However, expression of glutamine synthetase, glutamate synthase, and glutamate dehydrogenase showed an identical tendency of rising firstly and then falling owing to the substrate feedback inhibition referred. Refer to Figure 4 for the detailed results.

\section{Conclusions}

In this manuscript, we obtained the draft genome map of S. griseorubens JSD-1, a novel actinomycete that could utilize nitrate as its sole nitrogen source for growth by Illumina Miseq platform. Through BLASTP searches against $\mathrm{Nr}$ protein database, proteins involved in nitrate assimilation were picked out. All analyzed proteins were predicted to be intracellular enzymes and sequence alignments showed that these protein sequences were highly identical to those of their similar species. The same conclusion could also be drawn from their 3D structure modelings, both indicating the conservative character from their primary and secondary structures.

Since these analyzed proteins were determined to be located on the key positions of nitrogen signaling pathway, nitrate metabolism was inferred and summarized as: nitrate extracellular was transported into cells by membrane transporters. Reduction of nitrate to ammonia through assimilatory nitrate reductase and nitrite reductase were followed. Finally, ammonium was incorporated into carbon skeletons by glutamine synthetase, glutamate synthetase and glutamate dehydrogenase. Besides, expression patterns of these proteins were investigated by quantitative RT-PCR. Generally, nitrate reductase and nitrite reductase were up-regulated expressed when stimulated by nitrate. However, expression levels of glutamine synthetase, glutamate synthase or glutamate dehydrogenase reached the highest when the concentration of nitrate reached the threshold values $(30 \mathrm{mM}$ or $50 \mathrm{mM}$ ) which then led to the substrate feedback inhibition. Moreover, cultivation duration also had significant influence on expression responses of these nitrate assimilation proteins, with a consistently tendency of rising firstly and then falling for the shortage of substrate.

\section{Materials and methods}

Isolation, identification and characterization of the isolate The isolate was sourced from soil collected from Shanghai, China on a defined basal solid medium $(20.0 \mathrm{~g} / \mathrm{L}$ glucose, $10.0 \mathrm{~g} / \mathrm{L} \mathrm{KNO}_{3}, 1.0 \mathrm{~g} / \mathrm{L} \mathrm{MgSO}_{4}, 0.5 \mathrm{~g} / \mathrm{L} \mathrm{KH}_{2} \mathrm{PO}_{4}, 0.5 \mathrm{~g} / \mathrm{L}$ $\mathrm{NaCl}, 0.25 \mathrm{~g} / \mathrm{L} \mathrm{CaCl} 2,0.01 \mathrm{~g} / \mathrm{L} \mathrm{FeSO}_{4} \cdot 7 \mathrm{H}_{2} \mathrm{O}, 15.0 \mathrm{~g} / \mathrm{L}$ agar, $\mathrm{pH}$ 7.0). The strain was maintained on nutrient agar slants and then sun-cultured periodically.

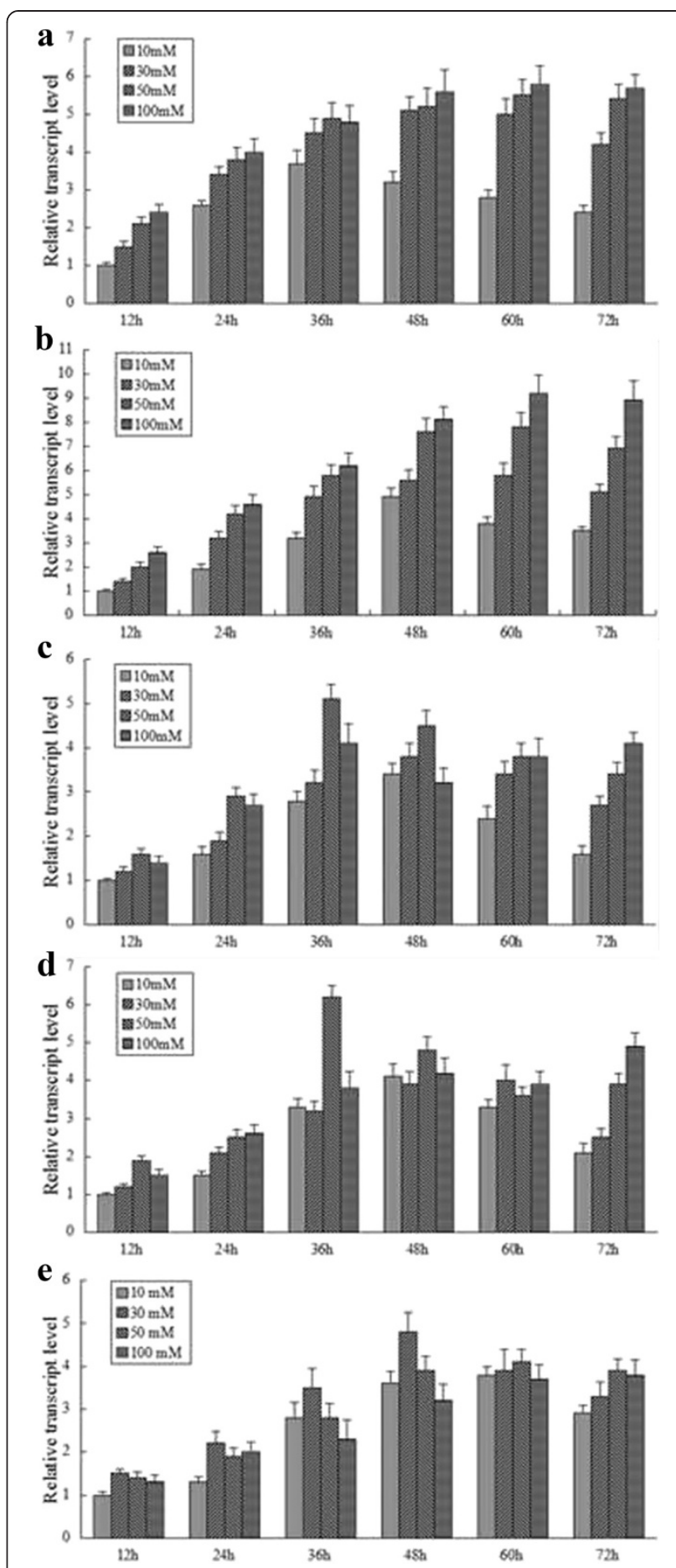

Figure 4 Differential expression patterns of the analyzed proteins when stimulated with nitrate. Figures are noted as a nitrate reductase, $\mathbf{b}$ nitrite reductase, $\mathbf{c}$ glutamine synthetase, d glutamate synthase, e glutamate dehydrogenase.

Genome DNA was extracted and purified from $2.5 \mathrm{ml}$ YEME cultures $(3.0 \mathrm{~g} / \mathrm{L}$ yeast extract, $5.0 \mathrm{~g} / \mathrm{L}$ tryptone, $3.0 \mathrm{~g} / \mathrm{L}$ malt extract, $10.0 \mathrm{~g} / \mathrm{L}$ glucose, and $340.0 \mathrm{~g} / \mathrm{L}$ sucrose, natural $\mathrm{pH}$ ) at $32^{\circ} \mathrm{C}$ for $48 \mathrm{~h}$ using Bacteria 
Genomic DNA Extraction Kit (TIANGEN, Beijing, China) for strain identification and genome sequencing. PCR amplification of $16 \mathrm{~S}$ rRNA gene of the isolate was performed and sequence obtained was used to search against the NCBI database (http://www.ncbi.nlm.nih.gov). In addition, morphological and physiological characteristics were also determined for identification.

To determine the capability of nitrate metabolism, nitrate content remained in the basal liquid medium $\left(100 \mathrm{mM} \mathrm{KNO}_{3}\right)$ were sampled and measured every $24 \mathrm{~h}$ during 7 days' cultivation at $32^{\circ} \mathrm{C}$ according to the instruction of AutoAnalyzer 3 (SEAL Analytical, Ltd). Technically triplicates were performed for quantification.

\section{Genome sequencing and functional annotation}

The genome sequencing of JSD-1 was performed by Illumina MiSeq $2 \times 250$ bp platform with insert sizes of $300 \mathrm{bp}, 360 \mathrm{bp}$, and $700 \mathrm{bp}$ paired-end as well as $3 \mathrm{~kb}$ and $8 \mathrm{~kb}$ mate-paired libraries. Assembly of all sequence reads applying Newbler 2.8 assembler resulted in a draft genome. Glimmer 3.0 were used to predict open reading frames (ORFs) with BLASTP annotation [30,31]. The functional annotation was determined with the KEGG, COG, and Swiss-Prot databases [32-34]. Finally, the draft genome map of the S. griseorubens JSD-1 was submitted to the GenBank for further investigation.

\section{Cellular localization}

After obtaining sequences of these nitrate assimilation proteins, their cellular localizations as well as signal peptide cleavage sites, were predicted by the online program SignalP 4.1 in fasta format [35].

\section{Multiple sequence alignment}

After comparing sequences of these nitrate assimilation proteins with the $\mathrm{Nr}$ database by BLASTP, the top three sequences with the most identities were picked out for sequence alignments. Alignments were performed by program ClustalX (Version 1.83) then results were further polished by the online program BoxShade (Version 3.21).

\section{Putative 3D structure modelings}

Putative 3D structures of these analyzed proteins were predicted by online program PHYRE 2.0 Server (http:// genome3d.eu/) in the intensive mode [36]. Protein sequences were used to search against the ExPDB template library. Sequences with the most identities were used for model generation. All 3D images were generated in JSmol colored by rainbow from $\mathrm{N}$ to $\mathrm{C}$ terminals [37].

\section{Expression patterns of the analyzed genes by quantitative RT-PCR}

Cultures collected from the basal medium with different concentrations $(10 \mathrm{mM}, 30 \mathrm{mM}, 50 \mathrm{mM}$, or $100 \mathrm{mM})$ of $\mathrm{KNO}_{3}$ were used to extract purified RNA. Total RNAs of S. griseorubens JSD-1 were obtained according to RNAprep Pure Bacteria Kit (TIANGEN, Beijing, China). Cells were sampled every $12 \mathrm{~h}$ within 3 days. Primers of these analyzed genes as well as $16 \mathrm{~S}$ rRNA gene were designed by DNAMAN 6.0. The details of primers and PCR products were listed in Table 4.

The reverse transcription PCR for cDNA was performed on the ABI StepOne ${ }^{\text {tw }}$ sequence detection system (PE Applied Biosystems, Foster City, USA). Quantitative RT-PCR was performed using the SYBR Green dye method according to the manufacturer's recommendations of SYBR ${ }^{\circ}$ Premix Ex Taq ${ }^{\text {Tu }}$ GC (TaKaRa, Dalian, China). Cycling parameters of quantitative RT-PCR reactions were programmed with an initial step of $30 \mathrm{~s}$ at $95^{\circ} \mathrm{C}$ followed by 40 cycles consisting of denaturation at $95^{\circ} \mathrm{C}$ for $10 \mathrm{~s}$, annealing at $60^{\circ} \mathrm{C}$ for $30 \mathrm{~s}$ and extension at

Table 4 Primers used for quantitative RT-PCR

\begin{tabular}{|c|c|c|c|}
\hline Gene & Primer $\left(5^{\prime}-3^{\prime}\right)$ & Target location & PCR size (bp) \\
\hline \multirow[t]{2}{*}{$16 \mathrm{~S}$ rRNA } & F: CGTATTCACCGCAGCAATGC & $94-179$ & 86 \\
\hline & R: GCGAGGTGGAGCGAATCTCA & & \\
\hline \multirow[t]{2}{*}{ NarB } & F: GACCTCTACGGCTGGCAGGC & $259-402$ & 144 \\
\hline & R: GCGGTCGTCAAGCAGGGT & & \\
\hline \multirow[t]{2}{*}{ NirD } & F: GCGTGGTCGTGCTGTGCGA & $101-207$ & 107 \\
\hline & R: CGCCAGGTCCGTCAGCGACA & & \\
\hline \multirow[t]{2}{*}{$G \ln A$} & F: GCTGAGCCTGATGGAACGCA & $1227-1322$ & 96 \\
\hline & R: GCCTCCCACTCCTGCTTCT & & \\
\hline \multirow[t]{2}{*}{ GltG } & F: CGGTGTGCCGTTCTGTCA & $150-269$ & 120 \\
\hline & R: AAGTTGTTCGTGGCGTGC & & \\
\hline \multirow[t]{2}{*}{ GdhH } & F: AAACTGCCGACTGGGACC & $82-189$ & 108 \\
\hline & R: GCGGTCGGTGAGGTCTTC & & \\
\hline
\end{tabular}


$72^{\circ} \mathrm{C}$ for $15 \mathrm{~s}$. The relative quantification of these genes was analyzed with the $2^{-\Delta \Delta \mathrm{Ct}}$ method. Technical triplicates were performed for each biological replicate, and the average values were used for quantification. Herein 16S rRNA was used as internal control to normalize the relative transcription of these analyzed genes.

\section{Additional files}

Additional file 1: Figure S1. Cellular localization of nitrate assimilation proteins. a nitrate reductase electron transfer subunit (NarB), b Nitrite reductase large subunit (NirD), c Glutamine synthetase $(G \ln A)$, d Glutamate synthase small subunit (GltG), e Glutamate dehydrogenase (GdhH).

Additional file 2: Figure S2. Multiple sequence alignment of nitrite reductase large subunit (NirC) from its similar species.

Additional file 3: Figure S3. Multiple sequence alignment of glutamine synthetase (GlnE) from its similar species.

Additional file 4: Figure S4. Multiple sequence alignment of glutamate synthase small subunit ( $\mathrm{Glt} \mathrm{G})$ from its similar species.

Additional file 5: Figure S5. Multiple sequence alignment of glutamate dehydrogenase $(\mathrm{GdhH})$ from its similar species.

Additional file 6: Figure S6. Putative 3D structure modelings of nitrate assimilation proteins. a Nitrate reductase electron transfer subunit $(\mathrm{NarB}), \mathrm{b}$ Nitrite reductase large subunit (NirD), c Glutamine synthetase $(\mathrm{G} \ln \mathrm{A})$, d Glutamate synthase small subunit (GItG), e Glutamate dehydrogenase $(\mathrm{GdhH})$.

\section{Competing interests}

The authors declare that they have no competing interests.

\section{Authors' contributions}

HF mainly participated in isolation, identification and characterization of this isolate. He also performed multiple sequence alignments, putative 3D structure modelings as well as genome analysis of S. griseorubens JSD-1. YS participated in the design of primers and conducted quantitative RT-PCR. $Y Z$ helped to draft the manuscript and gave advice on isolation and identification of this isolate. XW took part in the analysis of quantitative RT-PCR data and YL participated in isolation, preservation and characterization of this isolate. LM helped to draw partial figures of manuscript and conducted AA3 for the determination of nitrate concentration. PZ contributed to conceiving the study and participated in its design and coordination for the part of genome sequencing and quantitative RT-PCR analysis, and he also helped to draft the manuscript. All authors read and approved the final manuscript.

\section{Acknowledgements}

The research work was supported by the National High Technology Research and Development Program of China (2012AA101405) and Special Fund for Agro-scientific Research in the Public Interest of China (200903056).

\section{Author details}

'School of Agriculture and Biology, Shanghai Jiao Tong University, Shanghai 200240, China. ${ }^{2}$ Key Laboratory of Urban Agriculture (South), Ministry of Agriculture, Shanghai Jiao Tong University, Shanghai 200240, China. ${ }^{3}$ Bor S. Luh Food Safety Research Center, Shanghai Jiao Tong University, Shanghai 200240, China.

Received: 22 August 2014 Accepted: 24 November 2014

Published online: 10 December 2014

\section{References}

1. Moreno-Vivian C, Cabello P, Martinez-Luque M, Blasco R, Castillo F: Prokaryotic nitrate reduction: molecular properties and functional distinction among bacterial nitrate reductase. J Bacteriol 1999, 181(21):6573-6584.
2. Lledo B, Marhuenda-Egea FC, Martinez-Espinosa RM, Bonete MJ: Identification and transcriptional analysis of nitrate assimilation genes in the halophilic archaeon Haloferax mediterranei. Gene 2005, 361:80-88.

3. Richardson DJ: Bacterial respiration: a flexible process for a changing environment. Microbiol 2000, 146(3):551-571.

4. Richardson DJ, Berks BC, Russell DA, Spiro S, Taylor CJ: Functional, biochemical, and genetic diversity of prokaryotic nitrate reductase. Cell Mol Life Sci 2001, 58(2):165-178.

5. Masclaux-Daubresse C, Daniel-Vedele F, Dechorgnat J, Chardon F, Gaufichon $\mathrm{L}$, Suzuki A: Nitrogen uptake, assimilation and remobilization in plants: challenges for sustainable and productive agriculture. Ann Bot 2010, 105(7):1141-1157.

6. Lam HM, Coschigano KT, Oliveira IC, Melo-Oliveira R, Coruzzi GM: The molecular-genetics of nitrogen assimilation into amino acids in higher plants. Annu Rev Plant Physiol Plant Mol Biol 1996, 47:569-593.

7. Kent R, Belitz K, Burton CA: Algal productivity and nitrate assimilation in an effluent dominated concrete lined stream. J Am Water Resour As 2007, 41(5):1109-1128.

8. Siverio JM: Assimilation of nitrate by yeasts. FEMS Microbiol Rev 2006, 26(3):277-284

9. Ali AH, Hipkin CR: Nitrate assimilation in Candida nitratophila and other yeasts. Arch Microbiol 1986, 144(3):263-267.

10. Richardson DJ, Watmough NJ: Inorganic nitrogen metabolism in bacteria. Curr Opin Chem Biol 1999, 3(2):207-219.

11. Gonzalez PJ, Correia C, Moura I, Brondino CD, Moura JJG: Bacterial nitrate reductases: molecular and biological aspects of nitrate reduction. J Inorg Biochem 2006, 100(5-6):1015-1023.

12. Kanamori K, Weiss RL, Roberts JD: Ammino assimilation in Bacillus polymyxa. 15 N NMR and enzymatic studies. J Biol Chem 1987, 262(23):11038-11045.

13. Bird C, Wyman M: Nitrate/Nitrite assimilation system of the marine picoplanktonic cyanpbacterium Synechococcus sp. strain WH 8103: effect of nitrogen source and availability on gene expression. Appl Environ Microbiol 2003, 69(12):7009-7018.

14. Wu SQ, Chai W, Lin JT, Stewart V: General nitrogen regulation of nitrate assimilation regulatory gene nasR expression in Klebsiella oxytoca M5al. J Bacteriol 1999, 181(23):7274-7284.

15. Shi W, Lu W, Liu Q, Zhi Y, Zhou P: The identification of the nitrate assimilation related genes in the novel Bacillus megaterium NCT-2 accounts for its ability to use nitrate as its only source of nitrogen. Funct Integr Genomics 2014, 14(1):219-227.

16. Feng HW, Zhi YE, Shi WW, Mao L, Zhou P: Isolation, identification and characterization of a straw degrading Streptomyces griseorubens JSD-1. Afr J Microbiol Res 2013, 7(22):2730-2735.

17. Bentley SD, Chater KF, Cerdeño-Tárraga AM, Challis GL, Thomson NR, James KD, Harris DE, Quail MA, Kieser H, Harper D, Bateman A, Brown S, Chandra G, Chen CW, Collins M, Cronin A, Fraser A, Goble A, Hidalgo J, Hornsby T, Howarth S, Huang CH, Kieser T, Larke L, Murphy L, Oliver K, O'Neil S, Rabbinowitsch E, Rajandream MA, Rutherford K, et al: Complete genome sequence of the model actinomycete Streptomyces coelicolor A3 (2). Nature 2002, 417(6885):141-147

18. Ikeda H, Ishikawa J, Hanamoto A, Shinose M, Kikuchi H, Shiba T, Sakaki Y, Hattori M, Omura S: Complete genome sequence and comparative analysis of the industrial microorganism Streptomyces avermitilis. Nat Biotechnol 2003, 21(5):526-531.

19. Ohnishi Y, Ishikawa J, Hara H, Suzuki H, Ikenoya M, Ikeda H, Yamashita A, Hat-tori M, Horinouchi S: Genome sequence of the streptomycinproducing microorganism Streptomyces griseus IFO 13350. J Bacteriol 2008, 190(11):4050-4060

20. Han X, Li M, Ding Z, Zhao J, Ji K, Wen M, Lu T: Genome sequence of Streptomyces auratus strain AGR0001, a phoslactomycin-producing actinomycete. J Bacterio/ 2012, 194(19):5472.

21. Myronovskyi M, Tokovenko B, Manderscheid N, Petzke L, Luzhetskyy A: Complete genome sequence of Streptomyces fulvissimus. J Biotechnol 2013, 168(1):117.

22. Feng $H$, Zhi $Y$, Sun $Y$, Wei $X$, Luo $Y$, Zhou P: Draft genome sequence of a novel Streptomyces griseorubens strain, JSD-1, active in carbon and nitrogen recycling. Genome Announc 2014, 2(4):e00650-14.

23. Feng H, Sun Y, Zhi Y, Mao L, Luo Y, Wei X, Zhou P: Lignocellulose degradation by the isolate of Streptomyces griseorubens JSD-1. Funct Integr Genomics 2014. doi:10.1007/s 10142-014-0425-9. 
24. Skálová T, Dohnálek J, Østergaard LH, Østergaard PR, Kolenko P, Dusková J, Stepánková A, Hasek J: The structure of the small laccase from Streptomyces coelicolor reveals a link between laccases and nitrite reductases. J Mol Biol 2009, 385(4):1165-1178.

25. Beloqui A, Pita M, Polaina J, Martínez-Arias A, Golyshina OV, Zumárraga M, Yakimov MM, García-Arellano H, Alcalde M, Fernández VM, Elborough K, Andreu JM, Ballesteros A, Plou FJ, Timmis KN, Ferrer M, Golyshin PN: Novel polyphenol oxidase mined from a metagenome expression library of bovine rumen: biochemical properties, structural analysis, and phylogenetic relationships. J Biol Chem 2006, 281(32):22933-22942.

26. King BJ, Siddiqi MY, Ruth TJ, Warner RL, Glass ADM: Feedback regulation of nitrate influx in barley roots by nitrate, nitrite, and ammonium. Plant Physiol 1993, 102(4):1279-1286.

27. Bruning-Fann CS, Kaneene JB: The effect of nitrate, nitrite and $\mathrm{N}$-nitroso compounds on human health: a review. Vet Hum Toxicol 1993, 35(6):521-538.

28. Datta R, Sharma R: Temporal and spatial regulation of nitrate reductase and nitrite reductase in greening maize leaves. Plant Sci 1999, 144(2):77-83.

29. Trevisan S, Manoli A, Begheldo M, Nonis A, Enna M, Vaccaro S, Caporale G, Ruperti B, Quaggiotti S: Transcriptome analysis reveals coordinated spatiotemporal regulation of hemoglobin and nitrate reductase in response to nitrate in maize roots. New Phytol 2011, 192(2):338-352.

30. Delcher AL, Bratke KA, Powers EC, Salzberg SL: Identifying bacterial genes and endosymbiont DNA with Glimmer. Bioinformatics 2007, 23(6):673-679.

31. Altschul SF, Gish W, Miller W, Myers EW, Lipman DJ: Basic local alignment search tool. J Mol Biol 1990, 215(3):403-410.

32. Kanehisa M, Goto S, Furumichi M, Tanabe M, Hirakawa M: KEGG for representation and analysis of molecular networks involving diseases and drugs. Nucleic Acids Res 2010, 38(1):D355-D360.

33. Tatusov RL, Galperin MY, Natale DA, Koonin EV: The COG databases: a tool for genome-scale analysis of protein functions and evolution. Nucleic Acids Res 2000, 28(1):33-36.

34. Bairoch A, Apweiler R: The SWISS-PROT protein sequences database and its supplement TrEMBL in 2000. Nucleic Acids Res 2000, 28(1):45-48.

35. Petersen TN, Brunak S, von Heijne G, Nielsen H: Signal 4.0: discriminating signal peptides from transmembrane regions. Nat Methods 2011, 8(10):785-786.

36. Kelley LA, Sternberg MJE: Protein structure prediction on the web: a case study using the Phyre server. Nat Protoc 2009, 4(3):363-371.

37. Bienfait B, Ertl P: JSME: a free molecule editor in JavaScript. J Cheminform 2013, 5(24):363-371.

doi:10.1186/s12934-014-0174-4

Cite this article as: Feng et al:: Identification and characterization of the nitrate assimilation genes in the isolate of Streptomyces griseorubens JSD-1. Microbial Cell Factories 2014 13:174.

\section{Submit your next manuscript to BioMed Central and take full advantage of:}

- Convenient online submission

- Thorough peer review

- No space constraints or color figure charges

- Immediate publication on acceptance

- Inclusion in PubMed, CAS, Scopus and Google Scholar

- Research which is freely available for redistribution 